\title{
Sistema digestório das aves e o glicerol na dieta de frangos de corte: Revisão
}

\section{Denise Cerqueira de Sousa ${ }^{1}$, Nadja Lamonye Alves de Oliveira ${ }^{2}$, Leilane Rocha Barros Dourado $^{3}$, Guilherme José Bolzani de Campos Ferreira ${ }^{3}$ *}

Universidade Federal do Piauí, Campus "Prof. ${ }^{a}$ Cinobelina Elvas", Bom Jesus, PI, Brasil),

${ }^{I}$ Médico Veterinário, Mestrando em Zootecnia

${ }^{2}$ Médico Veterinário, Iniciação Científica

${ }^{3}$ Médico Veterinário, Docente do Curso de Zootecnia

*Autor para correspondência, E-mail: guilherme.ferreira@ufpi.edu.br.

RESUMO. A busca pela máxima eficiência alimentar, tem se tornado motivo de preocupação para avicultores e pesquisadores da área. Um alimento balanceado de maneira adequada para um animal é nutricionalmente completo quando: reduz o estresse, minimiza deficiências, melhora a competência imunológica e produz carcaça de qualidade, com melhor desempenho e maior lucratividade. Os fatores que nos levam a pesquisar o uso da glicerina na alimentação animal são a preocupação ambiental, devido a crescente produção de biodiesel, que acarreta aumento da glicerina gerada e o seu grande potencial energético, pois, a glicerina contém glicerol em sua composição, sendo que este possui alta energia bruta, tornando possível o uso da glicerina bruta como ingrediente energético incorporado em rações animais. O Sistema digestório das aves compreende os seguintes componentes: boca, esôfago, inglúvio (papo), estômago glandular (próventrículo), estômago mecânico (moela ou ventrículo), intestino delgado (formado por duodeno, jejuno e íleo), intestino grosso (cecos, colon e reto) e cloaca. Observa-se que os componentes com maior participação na glicerina são glicerol, água e lipídios. Glicerol é o principal componente da glicerina, sendo este altamente energético. Em dietas de frango de corte, o nível crítico recomendado de inclusão de glicerol é de $10 \%$, sendo que a adição de valores superiores a essa recomendação podem ocasionar redução de desempenho, além de afetar o metabolismo dos triglicerídeos, induzindo a adaptações bioquímicas e fisiológicas.

Palavras chave: Avicultura, glicerol, histologia

\section{Digestive system poultry and glycerol in the diet of broiler chickens Review}

ABSTRACT. The search for the maximum feed efficiency has become a concern for poultry producers and researchers. A properly balanced food for an animal is nutritionally complete when: reduces stress, reduces disability, improves immune competence and produces carcass quality, better performance and greater profitability. The factors that lead us to investigate the use of glycerin in animal feed are the environmental concern due to the increasing production of biodiesel. Which leads to an increase of glycerin generated and its large potential energy therefore contains glycerin glycerol into their composition, and that it has high gross energy, making possible the use of crude glycerin as an energy ingredient incorporated into animal feed. The digestive system of poultry comprises the following components: mouth, esophagus, crop, glandular stomach (proventriculus), mechanical stomach (gizzard or ventricle), small intestine (formed by the duodenum, jejunum and ileum), large intestine (cecum, colon and rectum) and cloaca. Observe that the components with the highest participation in glycerin are glycerol, water and lipids. Glycerol is the main component of glycerin, this being highly energy. In broiler diets, the critical level recommended inclusion of glycerol is $10 \%$, and adding values above this recommendation may result in performance degradation and affect the metabolism of triglycerides by inducing biochemical and physiological adaptations.

Keywords: glycerin, histology, poultry 


\section{Introdução}

A busca pela máxima eficiência alimentar, tem se tornado motivo de preocupação para avicultores e pesquisadores da área. Um alimento balanceado de maneira adequada para um animal é nutricionalmente completo quando reduz o estresse, minimiza deficiências, melhora a competência imunológica e produz carcaça de qualidade, com melhor desempenho e maior lucratividade (Butolo, 1998).

A nutrição pode ser considerada responsável pelo maior fator de custo de produção dos animais, portanto, a busca por novos ingredientes que forneçam bons índices desempenho e tenha um baixo custo, é constante.

Os fatores que nos levam a pesquisar o uso da glicerina na alimentação animal são a preocupação ambiental, devido a crescente produção de biodiesel, que acarreta aumento da glicerina gerada e o seu grande potencial energético, pois, a glicerina contém glicerol em sua composição, sendo que este possui alta energia bruta aproximadamente $4.320 \mathrm{Kcal} / \mathrm{kg}$ (Dozier et al., 2008), tornando possível o uso da glicerina bruta como ingrediente energético incorporado em rações animais.

Desde maio de 2008, de acordo com a Resolução no 02/2009 do Conselho Nacional de Política Energética (CNPE), publicada no Diário Oficial da União (DOU), a adição de biodiesel ao diesel passou de 3\% para 4\%. Isso resultou na produção de aproximadamente 120 mil toneladas de glicerina bruta, trazendo a preocupação a respeito do seu destino.

Segundo Henn \& Zanin (2009) a utilização de $1 \%$ de glicerina bruta originada da produção do biodiesel na composição das rações de aves e suínos, haveria um consumo de 480 mil toneladas de glicerina por ano, sendo assim uma potencial forma de destinação para o excesso de glicerina bruta.

Já existem várias pesquisas comprovando a eficácia da utilização da glicerina bruta no desempenho de frangos de corte (Cerrate et al., 2006; Menten et al., 2008; Gianfelici, 2009; Guerra, 2010; Santos 2013); porém não se sabe até o presente, o quanto esta influencia nos mecanismos fisiológicos do trato gastrointestinal desses animais, vale ressaltar que as características morfofisiológicas do sistema digestório das aves exerce influência direta sobre o melhor aproveitamento dos nutrientes, tendo em vista que é o sistema responsável por metabolizar e absorver os diferentes nutrientes ingeridos na dieta, melhorando assim o desempenho desses animais.

Diante do exposto, o objetivo desta pesquisa, foi avaliar a presença de possíveis alterações morfológicas no trato gastrointestinal de frangos de corte alimentados com dietas contendo o nível de inclusão de $7 \%$ de glicerina bruta na ração, como um ingrediente energético e caracterizar histologicamente o tubo digestório de frangos da linhagem Cobb $500^{\circledR}$.

\section{Revisão de literarura}

\section{Sistema digestório das aves}

O Sistema digestório das aves compreende os seguintes componentes: boca, esôfago, inglúvio (papo), estômago glandular (pró-ventrículo), estômago mecânico (moela ou ventrículo), intestino delgado (formado por duodeno, jejuno e íleo), intestino grosso (cecos, colon e reto) e cloaca. (Getty, 1986) (Figura 1). Esse difere fisiologicamente, dos de mamíferos, por diversas particularidades (Hoffmann \& Volker, 1969).

Nas aves a boca é formada pelo bico (palato inferior e superior), língua, glândulas salivares, coana e infundíbulo. O paladar e o olfato são menos desenvolvidos que nos mamíferos devido ao reduzido número de receptores químicos. Esta deficiência é compensada por células sensórias, localizadas no palato superior, chamadas de mecanoreceptores, que respondem ao estímulo do contato com o alimento (Bueno, 2006). O bico surge no oitavo dia de incubação (Boleli et al., 2008). O formato do bico varia conforme a dieta e as estratégias de forrageamento. Aves granívoras possuem um bico grosso que atua como um fórceps, esmagando os grãos; picapaus, um bico pesado e duro que atua como um cinzel para perfurar buracos; rapinantes, um bico afiado e em forma de gancho para dilacerar a carne; as galinhas possuem uma membrana serosa, somente na base do bico, que possui numerosas terminações sensitivas do nervo trigêmeo, que o converte em um órgão tátil. (Colville \& Bassert, 2010).

A língua é menos móvel do que a dos mamíferos. Seu tamanho e forma dependem da conformação do bico. Assim, as das galinhas são estreitas e pontiagudas. A língua está acima do osso hiode, formando um conjunto móvel. Os músculos linguais propriamente ditos, que 
constituem a base do órgão de referência são rudimentares, sendo assim, sua mobilidade se escassa. Na galinha, toda a língua está revestida por uma mucosa tegumentar cornificada, menos nas aves aquáticas. No dorso da língua das galinhas existe uma fila de papilas filiformes e cônicas direcionadas para trás. Na mucosa lingual há terminações nervosas, que servem para percepção tátil. A função da língua consiste de preensão, seleção e deglutição dos alimentos. (Hoffmann \& Volker, 1969). O esôfago é um tubo muscular que se estende da faringe até o estômago pelo lado direito do pescoço e desempenha a função de condução do alimento ao estômago (Colville e Bassert, 2010).

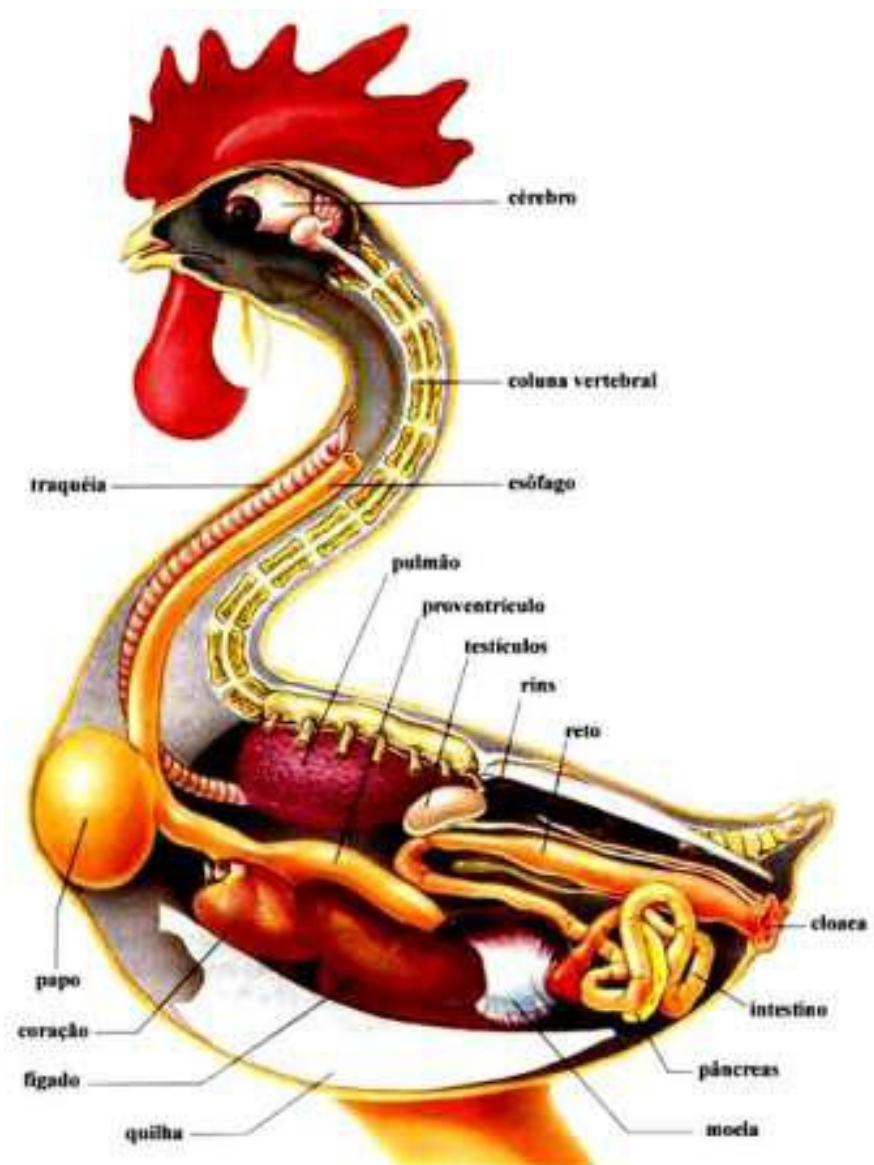

Figura 1. Trato digestório das aves. Fonte: http://www.portalsaofrancisco.com.br

O inglúvio é uma dilatação do esôfago onde os alimentos são armazenados e amolecidos. A entrada do bolo alimentar no inglúvio é controlada pelo tônus esofágico nesta região. Receptores de estiramento localizados na parede do inglúvio são estimulados pela distensão do órgão e ajudam no processo regulatório de ingestão (Macari et al., 1994). Segundo Colville e Bassert, (2010), o inglúvio tem função de armazenar, lubrificar e regular a passagem do alimento, é onde ocorre alguma fermentação e imbebição dos alimentos com mucosidades, preparando-os para a digestão gástrica posterior, permite a regurgitação de alimentos previamente digeridos para os filhotes.

O estômago das aves consiste em dois componentes separados: o estômago glandular e o estômago muscular. O mais anterior é glandular denominado proventrículo. É um órgão fusiforme, localizado entre o inglúvio e a moela (Sturkie, 1991). Essa estrutura é exclusiva das aves, e é onde a digestão química se inicia. A sua mucosa consiste de células epiteliais colunares e glândulas mucosas que produzem muco para o umedecimento do alimento. A camada submucosa possui glândulas digestivas, que secretam pepsina, que inicia a quebra das proteínas, e o ácido clorídrico, que eleva a acidez do estômago para aumentar a ação das enzimas digestivas (Colville \& Bassert, 2010).

O estômago muscular se adere a porção caudal do proventrículo e está coberto em seu extremo anterior por os lóbulos hepáticos. É grande, sua forma arredondada e apresenta um 
dos lados aplanados (Hoffmann \& Volker, 1969). Ele é formado por dois pares de músculos, uma musculatura mais delgada e outra mais grosseira, cujas contrações rítmicas, homogeneízam-se, maceram e projetam o alimento o alimento para próxima estrutura do trato digestório (Bueno, 2006). O estômago muscular denomina-se moela consiste em feixes separados de musculatura estriada que atuam para triturar os componentes alimentares. A espessura de sua parede varia conforme a dieta (Colville \& Bassert, 2010). Segundo Turk (1982), o tamanho da partícula é o regulador da passagem pela região pilórica, ou seja, o bolo alimentar permanecerá na moela até ser reduzido ao tamanho de $15-40 \mu \mathrm{m}$.

O fígado das aves é um órgão relativamente grande. Está dividido em lóbulos que confluem ao nível da veia cava posterior. $\mathrm{Na}$ porção anterior de ambos os lados envolve o coração atrás e lateralmente. $\mathrm{O}$ fígado estoca o excesso de gorduras e açucares, produz algumas proteínas, produz a bile para emulsificar gorduras e excreta metabólicos a partir do sangue (Hoffmann \& Volker, 1969).

O pâncreas consta de duas porções distintas no ponto de vista funcional: uma exócrina, que produz o suco pancreático, essencial para a digestão das proteínas, lipídios e carboidratos; e outra endócrina, cujos hormônios são de fundamental importância para manter a glicemia. As células produtoras de hormônio encontram-se agrupadas no próprio tecido do pâncreas e formam as ilhotas de Langerhans. O pâncreas é um órgão comprido, estreito e de aspecto claro; está situado dentro da alça duodenal (Hoffmann \& Volker, 1969).

O intestino delgado está dividido em três partes, duodeno, jejuno e íleo, as quais apresentam diferenças funcionais e morfológicas. O duodeno é a porção mais proximal que envolve o pâncreas. No duodeno há uma redução na espessura da mucosa, na direção do íleo, em função da diferença do tamanho dos vilos e da profundidade das criptas. Os vilos do duodeno são maiores, mais estreitos e com ápice arredondado, se comparados aos vilos do jejuno; já os vilos do íleo são menores e mais alargados (Mendes et al., 2004). O duodeno consiste de uma alça intestinal localizada logo após o ventrículo, sendo esta constituída de porção proximal descendente e porção distal ascendente. Sua localização é fácil devido a posição do pâncreas entre as duas porções da alça e seu maior diâmetro. Na porção ascendente é onde ocorre abertura dos ductos biliares e pancreáticos, conduzindo os sucos biliares e pancreáticos para o interior do intestino delgado (Boleli et al., 2008; Mclelland, 1975).

Os dois cecos originam-se na junção íleoceco-cólica e acompanham o íleo de modo retrógrado (Consins, 1985). O ceco é um par de saculações localizado na junção do intestino delgado e grosso em algumas espécies, sua função continua sendo estudada, mas é importante para reabsorção hídrica e fermentação bacteriana de celulose.

O intestino grosso é um segmento que se estende do final do intestino delgado até a coacla e sua principal função é reabsorção de água e minerais. A coacla localiza-se no final do trato digestório e divide-se em três partes. A parte anterior é a chamada de copródeo e recebe as fezes do intestino. $\mathrm{O}$ uródeo recebe os excrementos dos rins e dos ductos genitais. $\mathrm{O}$ proctódeo, localizado posteriormente, é acessado pelas duas outras partes e armazena os excrementos. A coacla é fechada por um orifício muscular que apresenta músculos ejetores potentes para eliminação das excretas através de uma abertura denominada ânus. Os resíduos organizam-se em excreta, que consiste em uma região central escura das fezes, circundada por um anel de urato (Colville \& Bassert, 2010).

\section{Histologia do Sistema Digestório das aves}

$\mathrm{O}$ trato digestório das aves difere morfologicamente dos mamíferos em vários aspectos. No início da cavidade oral ao invés de lábios e dentes, essas possuem um bico cornificado acoplado ao maxilar e à mandíbula (Getty, 1986)

O tipo de epitélio que reveste a cavidade oral e língua é o epitélio pavimentoso estratificado queratinizado. Dentro da lâmina na submucosa da cavidade oral, existem glândulas semelhantes às salivares, pouco desenvolvidas, tendo formato tubular ramificado simples e secreção mucosa. A língua das aves tem forma estreita e cônica, possui um cerne de músculo esquelético, glândulas mucosas e o osso entoglosso, mais caudalmente (Banks, 1991).

O epitélio que reveste tanto o esôfago como o inglúvio é pavimentoso estratificado intensamente queratinizado. A lâmina própria é formada por epitélio conjuntivo frouxo com tecido linfático difuso e alguns nódulos 
linfáticos. $\mathrm{O}$ acúmulo de tecido linfático é mais evidente na região do inglúvio. A membrana mucosa forma dobras longitudinais. A muscular da mucosa é formada por uma massa ondulada de músculo liso orientanda em sentido longitudinal. Glândulas mucosas túbuloalveolares ramificadas estão presentes no esôfago e ausentes no inglúvio. O inglúvio é um divertículo esofagiano, sendo que seu epitélio é mais espesso que o do esôfago. As túnicas do esôfago e do inglúvio são submucosa, muscular, adventícia e serosa (Banks, 1991).

O proventrículo é o estômago glandular das aves. Projetando-se para o lúmen, há várias papilas, baixas e largas, visíveis macroscopicamente, tendo cada uma um ducto de excreção responsável pela liberação de suco gástrico ácido e proteolítico (ácido clorídrico e pepsina) para a digestão química (Dyce et al., 2004). Retirando-se a serosa e a camada muscular do proventrículo, é possível observar as extremidades cegas das volumosas glândulas que, em conjunto, têm aspecto de mosaico, o mesmo observado em Coragyps atratus brasiliensis por Menin et al. (1990).

O ventrículo é a porção do sistema digestivo que está conectada ao proventrículo por um istmo estreito, estando ausentes as glândulas submucosas. A superfície luminal está revestida por um produto de secreção queratinóide, produzido pelas glândulas mucosas. $\mathrm{O}$ revestimento da túnica mucosa é formado por células prismáticas baixas com núcleos esféricos e basalmente localizados. As células superficiais se continuam no interior das glândulas e são substituídas por células semelhantes às caliciformes. As glândulas mucosas são retas e tubulares. As camadas do ventrículo estão caracterizadas da seguinte forma: lâmina própria e a submucosa são típicas, já a túnica muscular não é típica, ela é formada por músculo liso e por tecido conjuntivo denso. A margem lateral do ventrículo é formada por tecido conjuntivo denso modelado, sendo que o músculo conjuntivo se origina deste tecido e se espalha por toda a túnica muscular. A túnica serosa é fina (Banks, 1991).

O intestino delgado das aves é formado por três camadas: a membrana mucosa, formada por uma camada superficial de epitélio colunar simples, uma de tecido conjuntivo de ligação e uma lâmina própria; a submucosa é, composta de uma discreta camada de tecido conjuntivo frouxo; e a membrana serosa, caracterizada por um epitélio composto de células lisas e finas sobre uma camada de tecido conjuntivo frouxo, que possui poucas e pequenas fibras elásticas, é nesta região que os vasos sanguíneos e nervos associam-se a camada do mesentério (Hodges, 1974 e Boleli, 2008) (Figura 2).

O intestino possui quatro túnicas a mucosa, a submucosa, a muscular e a serosa. A mucosa inclui o epitélio de revestimento, a lâmina própria, as glândulas, a muscular da mucosa e os vilos. Os vilos são projeções da mucosa, estes são recobertos por epitélio colunar simples e estão presentes no intestino delgado e grosso. São maiores no intestino delgado e diminuem gradualmente de altura e se tornam mais largos ao longo do intestino. A submucosa é uma camada de tecido conjuntivo que é mais densa que a lâmina própria, sendo extremamente fina nas galinhas. A túnica muscular consiste de uma camada de músculo liso interna circular e externa longitudinal, uma terceira camada de músculo liso pode estar presente nas aves. A serosa recobre todo o intestino consistindo de uma camada de tecido conjuntivo coberto por mesotélio. Nas aves há ausência de glândulas duodenais (Glândulas de Brunner), entretanto tecido linfático é particularmente abundante (Aughey \& Frye, 2001; Bacha \& Bacha, 2003; Frappier, 2007).

A membrana mucosa do intestino delgado apresenta várias estruturas que aumentam sua superfície e consequentemente aumentam a área de absorção dos nutrientes; uma dessas estruturas são as vilosidades intestinas, que são projeções alongadas da mucosa (epitélio e lâmina própria) em direção ao lúmen do intestino delgado (Junqueira, 2003). As vilosidades variam de número, forma e tamanho de acordo com a região que se encontram (Junior \& Bacha, 2003), sendo que, a mucosa torna-se mais delgada no sentido do duodeno para o íleo, e consequentemente as vilosidades tornam-se mais curtas e a profundidade das criptas de Lierberkuhn diminui (Dukes, 2006), as criptas de Lierberkuhn são ductos que se abrem entre a base do vilo e a muscular da mucosa (Hodges, 1974; Junior e Bacha, 2003), as criptas possuem células-tronco, algumas células absortivas, células caliciformes, e células enteroendócrinas (Junqueira, 2003); ao contrário dos ruminantes, equinos e do homem as aves não possuem células de Paneth, que são células piramidais especializadas em desempenhar a função fagocitária (Banks, 1991) 


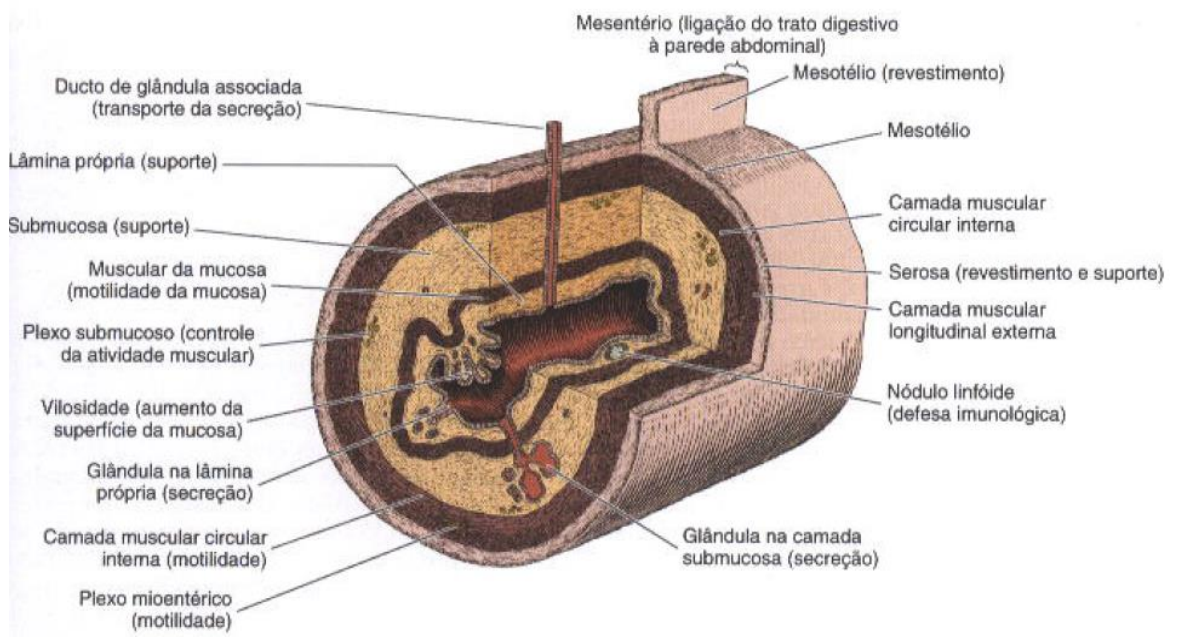

Figura 2: Estrutura esquemática de uma porção do trato digestivo com diversos componentes e suas funções. (Redesenhado e reproduzido, com permissão a partir de Bevelander G: Outline of Histology, $7^{\mathrm{a}}$ ed. Mosby, 1971). Fonte: Junqueira, 2003.

Segundo Eroschenko (2008), os vilos são constituídos por três tipos de células funcionalmente distintas: os enterócitos, as células caliciformes e as células enteroendocrinas.

As células-tronco são colunares baixas com núcleos ovais próximos as bases das células. Estas células possuem elevada taxa de mitose, algumas se movem para superfície, no processo de renovação das células superficiais; outras migram para as glândulas e se diferenciam em células mucosas ou parietais, zimogênicas ou enteroendócrinas (Junqueira, 2003). Em frangos a proliferação de enterócitos não é restrita à região da cripta, mas também ocorre ao longo do vilo (Uni et al., 1998).

A taxa de turnover refere-se à velocidade de renovação celular, e esta dependente do processo de proliferação, migração e extrusão celular. $\mathrm{O}$ tempo necessário para o enterócito migrar da base até o ápice das vilosidades aumenta com a idade, levando aproximadamente 72 horas em pintos de quatro dias e 96 horas em aves mais velhas (Uni et al., 2006; Smith, Beal, 2008).

A proliferação, migração, diferenciação e maturação das células-tronco nas criptas são reguladas por uma variedade de fatores, incluindo nutrientes no lúmen intestinal, hormônios gastrointestinais tróficos, fatores de crescimento e citocinas (Marshman et al., 2002).

Os enterócitos, ou células de absorção, são células tipicamente colunares, que respondem pela digestão final do alimento e pelo transporte transepitelial dos nutrientes a partir do lúmen e/ou para o lúmen. A superfície apical apresenta vários microvilos que lhe proporcionam maior superfície de contanto com a digesta e, portanto, maior superfície de digestão, absorção e secreção.

As células caliciformes são secretoras de glicoproteínas (muco) que possuem o papel primário de proteger o epitélio intestinal da ação de enzimas digestivas e efeitos abrasivos da digesta durante o desenvolvimento embrionário e após a eclosão, outra função e a de barreira contra patógenos. As células enteroendócrinas são produtoras de hormônios (gastrina, colecistoquinina, secretina, polipeptídeo inibidor gástrico) e monoaminas biogênicas, produtos estes que participam na regulação da digestão, absorção e utilização de nutrientes (Boleli et al., 2002).

A lâmina própria e a túnica submucosa contêm grande quantidade de tecido linfoide nodular e difuso. Este pode se agregar na região caudal de formando as placas de Peyer. As placas de Peyer compreendem agregados linfóides, estas fornecem um local importante para o contato entre antígenos e tecidos linfoides. São semelhantes as placas de Peyer dos mamíferos em muitos aspectos (Befus et al., 1980; Mowat, 2003; Yun et al., 2000).

Os cecos são dois apêndices em fundo cego, localizados entre a junção do intestino delgado e intestino grosso. Os vilos estão presentes nos intestinos, mas diminuem e desaparecem ao final do órgão. A lâmina própria e a túnica submucosa 
possuem muito tecido linfóide nodular e difuso. $\mathrm{O}$ acúmulo de nódulos nos orifícios cecais é denominado tonsila cecal. A junção deste órgão às outras junções do intestino é circunscrita por um esfíncter formado pela camada circular interna da túnica muscular. Os cecos são responsáveis pela absorção de água e digestão das fibras. A morfologia do reto é semelhante ao intestino delgado, porém possui vilos curtos e espessos, com uma quantidade elevada de células caliciformes (Banks, 1991).

\section{Glicerina e Glicerol: conceitos}

Oliveira et al (2013), observaram que os componentes com maior participação na glicerina são glicerol, água e lipídios. Glicerol é o principal componente da glicerina, sendo este altamente energético. É encontrado em alimentos e no metabolismo animal e tem potencial de uso como substituto parcial dos grãos de cereais ou outros ingredientes ricos em amido na alimentação animal (Defrain et al., 2004 e Lammers et al., 2008).

Glicerol é o nome comum do composto orgânico 1,2,3-propanotriol, descoberto por Carl W. Scheele em 1779 durante a separação de uma mistura aquecida de $\mathrm{PbO}$ preparada com óleo de oliva. Os seus sinônimos são glicerina, trihidroxipropano, glicilálcool, gliceril e 1,2,3trihidroxipropano. Na natureza, o glicerol existe em vegetais (soja, mamona, babaçu, girassol, palma, algodão, coco, dendê, pinhão manso) $\mathrm{e}$ animais em formas combinadas de glicerina com ácidos graxos. O glicerol é também um composto considerado fundamental dentro do sistema metabólico de microrganismos; onde atua como precursor de numerosos compostos; e como regulador de vários mecanismos bioquímicos intracelulares (Lages, Silva-Graça, Lucas, 1999).

Segundo a União Internacional da Química Pura e Aplicada - IUPAC (1993) o glicerol é um composto orgânico pertencente à função álcool, líquido à temperatura ambiente $\left(25^{\circ} \mathrm{C}\right)$, higroscópico, inodoro, viscoso e de sabor adocicado.

\section{Glicerina na Alimentação Animal}

A utilização da glicerina bruta na formulação de rações para aves e suínos desperta interesse imediato por se constituir em um produto rico em energia (4.320 kcal de energia bruta por $\mathrm{kg}$ para o glicerol puro) e com alta eficiência de utilização pelos animais. Usada como fonte de energia para monogástricos, a glicerina pode ser oxidada gerando um rendimento de 22 moles de ATP/mol segundo Doppenberg \& Van Der Aar (2007). O glicerol pode ser utilizado como ingrediente energético em rações para suínos em crescimento e terminação em níveis de até $9 \%$, não influencia as características de carcaça nem a qualidade da carne dos animais (Berenchtein et al., 2010).

Outro aspecto que justifica a aplicação desse co-produto da indústria de biodiesel na produção de alimentos para animais é que parte das matérias primas renováveis produzidas para atender finalidades energéticas retornarão à cadeia alimentar para gerar produtos de alto valor nutricional. Além de servir como fonte de energia, o glicerol também pode ter efeitos positivos sobre a retenção de aminoácidos ou nitrogênio, (Cerrate, 2006); a ação do glicerol inibindo a atividade das enzimas fosfoenolpiruvato carboxiquinase e glutamato desidrogenase pode resultar em economia dos aminoácidos gluconeogênicos e favorecer a deposição de proteína corporal.

O glicerol, além de ser uma fonte energética, pode ser empregado nas dietas para melhorar a qualidade dos peletes (granulado) das rações. Groesbeck (2002), trabalhando com dietas de suínos, demonstrou que a inclusão de glicerol melhorou a qualidade dos peletes e diminuiu o custo energético da peletização, obtendo os melhores resultados com 3 e $6 \%$ de glicerol adicionado. $\mathrm{O}$ glicerol também pode reduzir o pó das dietas e dos suplementos minerais e vitamínicos e devido ao sabor adocicado, pode ter melhorar a palatabilidade da dieta e consequentemente o consumo de ração, atuando de maneira positiva no desempenho dos animais. (Piesker E Dersjant-Li, 2006; Groesbeck et al., 2008).

Há uma demanda mundial por fontes energéticas renováveis, pois causam menor impacto ao meio ambiente com sua emissão reduzida de gases causadores do efeito estufa após sua queima, constitui alternativa ao petróleo. A energia tornou-se, no cenário atual, um fator fundamental para o desenvolvimento dos países, haja vista a dependência no emprego de tecnologias promotoras do desenvolvimento socioeconômico local. Entretanto, do total da energia consumida em todo o mundo, cerca de $90 \%$ provém de fonte fóssil, sendo esta esgotável. Com isso, vislumbra-se cada vez mais a necessidade em se pesquisar e desenvolver novas 
fontes alternativas de energia, tal como o biodiesel, como forma de ampliar e diversificar a oferta energética, de maneira ambientalmente sustentável (Sousa, 2006).

No Brasil é notável o aumento na produção de biodiesel, segundo a Agência Nacional do
Petróleo, Gás Natural e Combustível através do seu Anuário Estatístico 2013, têm demonstrado um excelente progresso nos últimos anos e, como consequência aumento também na quantidade de glicerina gerada (figura 3 e figura 4 )

\section{Evolução da produção de biodiesel (B100) - 2005-2012}

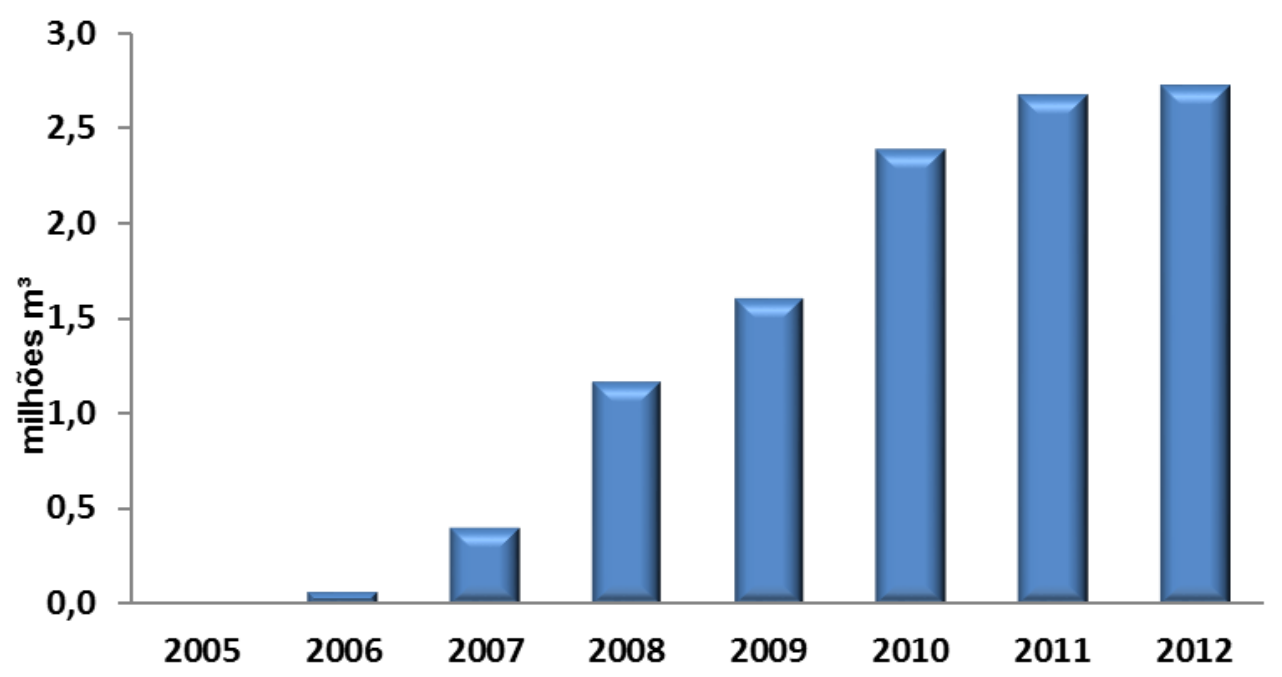

Fonte: ANP/SPD

Figura 3: Evolução da produção de biodiesel de 2005-2012.

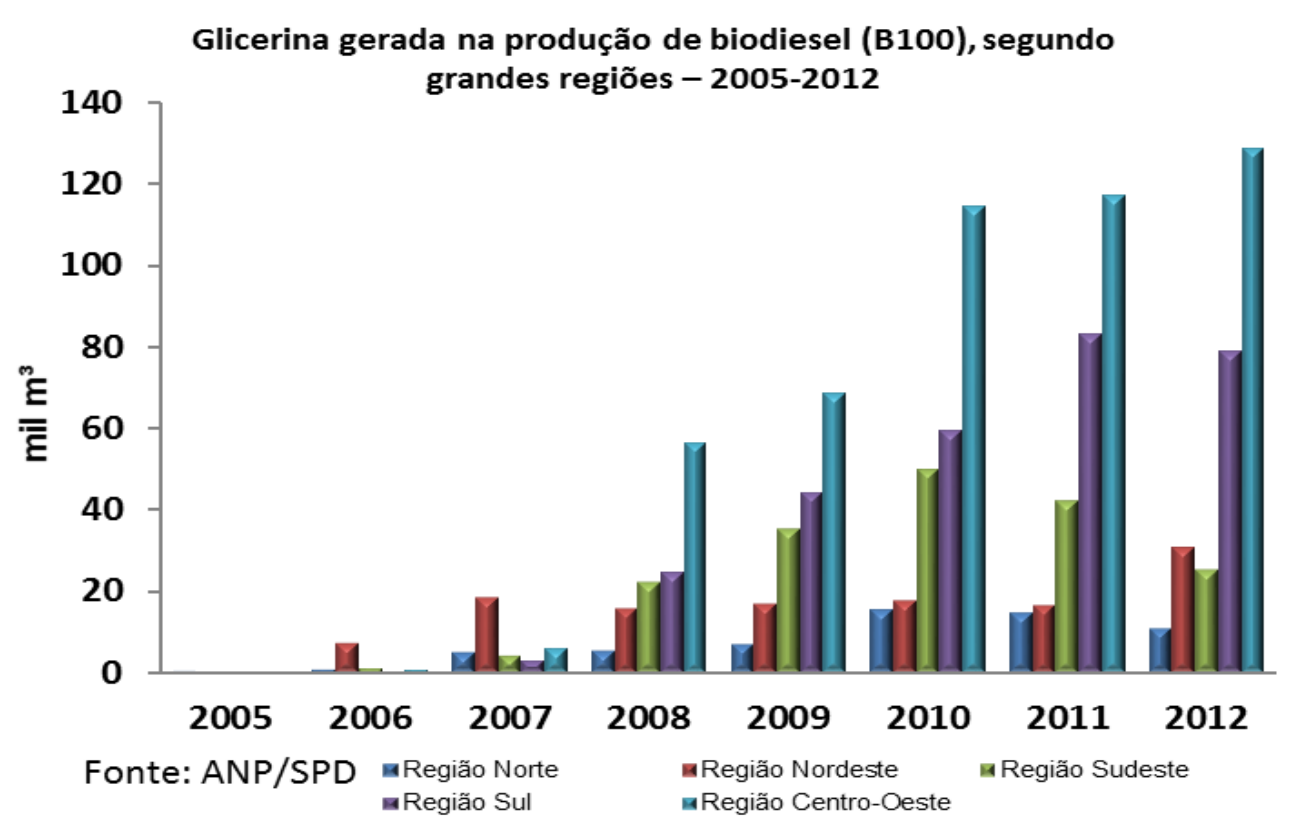

Figura 4: Glicerina gerada na produção de biodiesel de 2005-2012.

Pinto (2005) descreve que a glicerina bruta apresenta impurezas provindas de reagentes como a água, catalisadores (alcalino ou ácido), álcoois (etanol ou metanol), ácidos graxos livres, ésteres, propanodióis, monoéteres, oligômeros de glicerina e polímeros.
São necessários processos complexos e de alto custo para que a glicerina bruta alcance as exigências em grau de pureza necessária para fins alimentícios e farmacêuticos (Diniz, 2005). 
De acordo com o Ministério da Agricultura, Pecuária e Abastecimento, a glicerina bruta pode ser utilizada na alimentação animal como ingrediente das rações, desde que, contenha no máximo $150 \mathrm{ppm}$ de metanol, $12 \%$ de umidade e no mínimo $80 \%$ de glicerol. Segundo Arruda (2007), é permitido o uso de glicerol como aditivo em alimentos, considerado como atóxico quando usado dentro dos limites de recomendação.

Cerrate (2006) afirma que apesar das impurezas, a utilização da glicerina bruta na alimentação animal pode ser uma excelente alternativa para a destinação deste subproduto, por tratar-se de um produto energético, com efeito sobre a retenção de aminoácidos e favorecimento na deposição de proteína.

Segundo Henn e Zanin (2009), a utilização de $1 \%$ de glicerina bruta originada da produção do biodiesel na composição das rações de aves e suínos, haveria um consumo de 480 mil toneladas de glicerina por ano, sendo assim uma potencial forma de destinação para o excesso de glicerina bruta.

\section{Metabolismo do glicerol em aves}

Segundo Mourot et al. (1994), glicerol é um precursor para a síntese de triacilgliceróis e de fosfolípidos, no fígado e no tecido adiposo. Quando o corpo usa a gordura acumulada como fonte de energia, glicerol e ácidos graxos são libertados na corrente sanguínea. O glicerol pode ser convertido em glicose pelo fígado, providenciando energia para o metabolismo celular. Antes que possa entrar na via da glicólise ou da gliconeogênese, dependendo das condições fisiológicas, tem que ser convertido em gliceraldeído-3-fosfato, pela enzima glicerol quinase presente apenas no fígado. $\mathrm{O}$ glicerol não pode ser reaproveitado pelos adipócitos, que não têm glicerol quinase, sendo então liberado na circulação (Marzzoco \& Torres, 2007). Em tecidos adiposos, o glicerol 3-fosfato é obtido da dihidroxiacetona fosfato por meio da ação da enzima glicerol-3-fosfato desidrogenase. $\mathrm{O}$ glicerol liberado no catabolismo do triacilglicerol é convertido a glicose no fígado por meio de fosforilação em glicerol-3 - fosfato catalisado pela glicerol quinase iniciando então a gliconeogênese .

Kato (2005) descreve que em monogástricos, a glicerina consumida é absorvida por via paracelular nos enterócitos por difusão passiva, e há evidências de que em ratos, este processo de transporte seja sódio dependente $(\mathrm{Na}+)$, no intestino delgado. Independente do mecanismo de absorção, o glicerol vai ao fígado pela veia porta e atua como um precursor de gliconeogênico como no caso do glicerol endógeno liberado pelo catabolismo de triacilgliceróis.

Demonstração do metabolismo do glicerol no fígado quando o organismo está em déficit de energia e quando está suprido conforme (Best 2006) na figura 5.

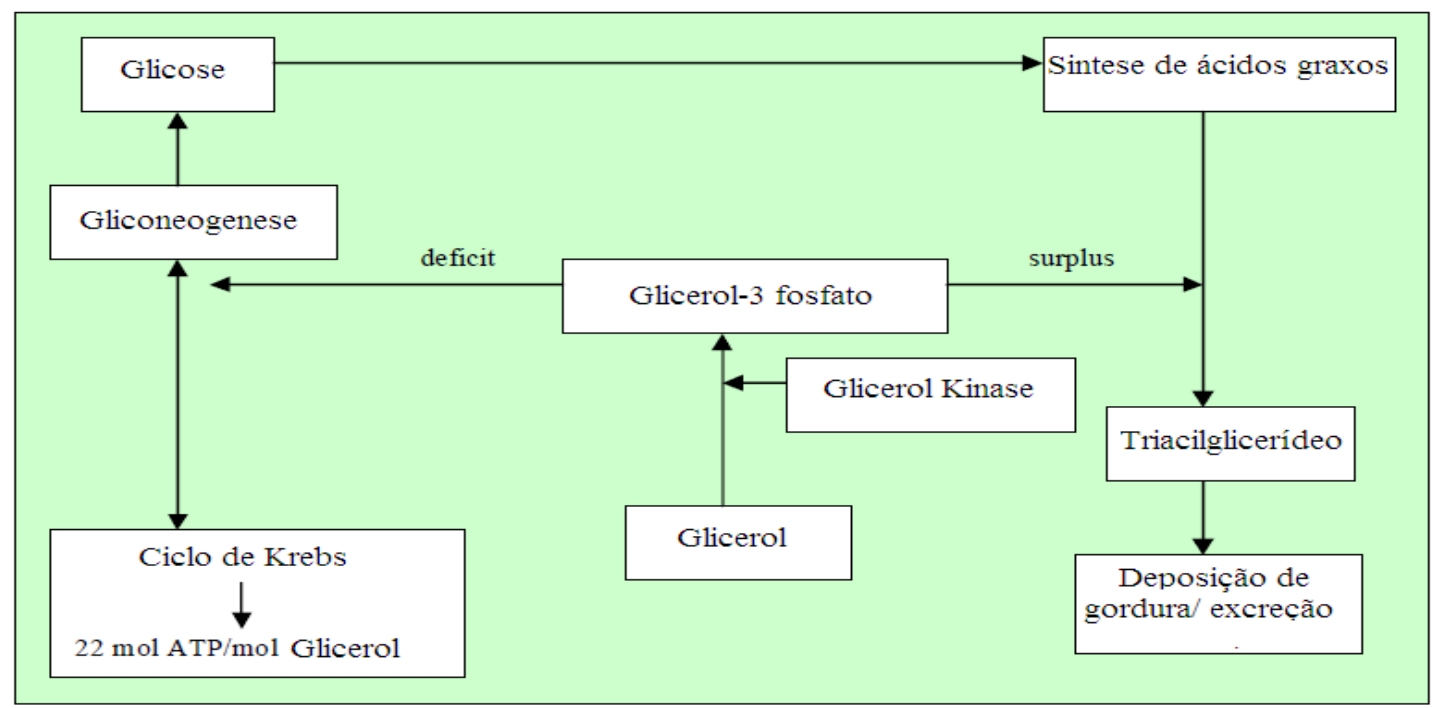

Figura 5: Metabolismo hepático do glicerol em função do estado alimentar do organismo segundo Best (2006).

Da mesma forma que o glicerol endógeno proveniente do catabolismo do triacilglicerol, o glicerol proveniente da dieta que chega ao fígado através da veia porta será metabolizado para 
produção de glicose. $\mathrm{O}$ glicerol resultante da hidrólise de triacilglicerol no tecido adiposo é liberado para o sangue e transportado para o fígado, as proteínas de membrana aquagliceroporinas fazem o carreamento do glicerol nas membranas do fígado e dos adipócitos. Os níveis dessas proteínas são regulados pelo nível plasmático de insulina, o qual também funciona como regulador dos níveis de glicerol quinase e consequentemente da gliconeogênese (Maeda et al., 2008).

Em dietas de frango de corte, o nível crítico recomendado de inclusão de glicerol é de $10 \%$, sendo que a adição de valores superiores a essa recomendação podem ocasionar redução de desempenho (Cerrate et al., 2006), além de afetar o metabolismo dos triglicerídeos, induzindo a adaptações bioquímicas e fisiológicas (Dasari, 2007).

A inclusão elevada de glicerol nas dietas pode exceder a capacidade da enzima glicerol quinase, indicando saturabilidade do glicerol (Kato et al., 2005) e limitando sua absorção (Min et al., 2010). O glicerol não absorvido é excretado na urina (Dasari, 2007) e promove o aumento da taxa de passagem da digesta, comprometendo a utilização dos nutrientes (Gianfelici, 2009).

\section{Referências Bibliográficas}

Arruda, P.V., Rodrigues, R.C.L.B. \& Felipe, M.G.A. 2007. Glicerol: um subproduto com grande capacidade industrial e metabólica. Revista Analytica. $\mathrm{n}^{\circ} 26$.

Aughey, E. \& Frye, F.L. 2001. Digestive system. Comparative veterinary histology: with clinical correlates. London: Manson Publishing Ltd., 8, 97-136.

Bacha W.J. \& Bacha, L.M. 2003. Atlas colorido de histologia veterinária. $2^{\mathrm{a}}$ ed., Roca, São Paulo, Brasil, 457p.

Befus, A.D., Johnston, N., Leslie, G.A. \& Bienenstock, J. 1980. Gut-associated lymphoid tissue in the chicken. I. Morphology, ontogeny and some functional characteristics of Peyer's patches, 25, 26262632.

Behmer, O.A. Tolosa, E.M.C. \& Freitas Neto, A.G. 1976. Manual de técnicas para histologia normal e patológica. Edart, São Paulo, 241p.

Berenchtein B., Costa, L.B., Braz, D.B., Almeida, V.V., Tse, M.L.P. \& Miyada, V.S.
2010. Utilização de glicerol na dieta de suínos em crescimento e terminação. Revista Brasileira de Zootecnia, 39, 1491-1496.

Best, P. 2006. Increased biofuel production will grow supplies of by-products: Glycerine gives an energy option. Feed International, 27, 2021.

Boleli, I.C., Maiorka, A. \& Macari, M. 2008. Estrutura funcional do trato digestório. In: Marcos Macari; Renato Luís Furlan; Elisabeth Gonzales. (Org.). Fisiologia Aviária Aplicada a frangos de corte. 2 ed. Jaboticabal: Funep, 75-98.

Bueno, F.L. 2006. Efeito da forma física, granulometria (DGM) e adição de óleo em dietas iniciais de frangos. Dissertação (Mestrado em Ciências Veterinárias), Universidade Federal do Paraná, Curitiba.

Butolo, J.E. 1998. Agentes antimicrobianos em rações de aves e suínos. In: Simpósio sobre Aditivos na Produção de Ruminantes e NãoRuminantes: Anais... Wechsler, F.S., ed. XXXV Reunião Anual da Sociedade Brasileira de Zootecnia. Botucatu, SP. pp. 237-254.

Cerrate, S., Yan, F., Wang, Z., Coto, C., Sakakli, P. \& Waldroup, P.W. 2006. Evaluation of glycerine from biodiesel production as a feed ingredient for broilers. International Journal of Poultry Science, 5, 1001-1007.

CNPE - Conselho Nacional de Política Energética. [2009]. RESOLUÇÃO CNPE No 2, Publicada na seção 1 do DOU de 15 de maio de 2009. Disponível em: www.udop.com.br/.../res_02_(2009)_adicao_ biodiesel_diesel.pdf. < Acesso em: Julho 28 de 2015

Colville, T \& Bassert, J.M. 2010. Anatomia e Fisiologia Clínica para Medicina Veterinária. Rio de Janeiro. Editora: Elsevier.

Consins, R.J. 1985. Absorption, transport, and hepatic metabolism of copper and zinc: special reference to metallothionein and ceruloplasmim. Physiology Review, 65, 238309.

Defrain, J.M., Hippen, A.R., Kalscheur, K.F. \& Jardon, P.W 2004. Feeding glycerol to transition dairy cows: effects on blood metabolites and lactation performance. Journal of Dairy Science, 87, 4195-4206. 
Diniz, G. 2005. De coadjuvante a protagonista: glicerina bruta obtida na produção de biodiesel pode ter muitas aplicações. Ciência Hoje, Disponível em: http://cienciahoje.uol.com.br/noticias/quimica /de-coadjuvante-a-

protagonista/?searchterm=glicerina. Acesso em: Julho 28 de 2015.

Doppenberg, J. \& Van Der Ar, P. 2007. The nutritional value of biodiesel by-products (Part 2: Glycerine). Feed Business Asia, 4243.

Dozier, W.A., Kerr, B.J., Corzo, A. Kidd M.T., Weber T.E. \& Bregendahl K. 2008. Apparent Metabolizable Energy of Glycerin for broiler Chickens. International Journal of Poultry Science, 87, 317-322.

Dukes, G.E. 2006. Digestão aviária. In: Trampel, D.M., Dukes, G.E. Fisiologia dos animais domésticos, 10. Ed. Rio de Janeiro: Guanabara Koongan, 23, 450-461.

Eroschenko, V. 2008. Atlas of histology: with functional correlations. 11 ed. Philadelphia: Lippincott Williams \& Wilkins, 532 p.

Frappier, B.L. 2007. Digestive system. In: Eurell, J.A., Frappier, B.L. Dellman's Textbook of Veterinary Histology. 6.ed. Hoboken: WileyBlackwell, 10, 170-210.

Getty, R. 1986. Anatomia dos animais domésticos, Rio de Janeiro, 5ed. Interamericana, v.2.

Gianfelici, M.F. 2009. Uso de glicerol como fonte de energia para frangos de corte. Dissertação (Mestrado em Zootecnia). Universidade Federal do Rio Grande do Sul/Faculdade de Agronomia, Porto Alegre, $129 f$

Groesbeck, C.N. 2002. The Effect of Feed Ingredients on Feed Manufacturing and Growth Performance of Pigs. krex.ksu.edu/dspace/bitstream/2097/523/1 /CrystalGroesbeck2007.pdf.pdf> Acesso em: Julho 28 de 2015

Groesbeck, C.N., McKinney, L.J., Derouchey, J.M., Tokach, M.D., Goodband, RD, Dritz, S.S., Nelssen, J.L., Duttlinger, A.W., Fahrenholz, A.C. \& Behnke, K.C. 2008. Effect of crude glycerol on pellet mill production and nursery pig growth performance. Journal of Animal Science, 85, 2228-2236.
Guerra, R.L.H. 2010. Glicerina bruta na alimentação de frangos de corte. Dissertação de Mestrado em Zootecnia. Universidade Estadual de Maringá.

Henn, J.D. \& Zanin, A.O 2009. Agronegócio do Biodiesel: Potencialidades e limitações da utilização da glicerina (co-produto) na alimentação de suínos e de aves. In: 47 Congresso da SOBER, Porto Alegre. SOBER 47 Congresso da Sociedade Brasileira de Economia, Administração e Sociologia Rural. Porto Alegre: UFRGS. v. 1.

Hodges, R.D. 1974. The digestive system: The digestive tract. The histology of the fowl. Londom: academic press, 35-36.

Hoffmann, G., Volker, H. 1969. Anatomía y Fisiología de las Aves Domésticas. Zaragoza (Espanã). Editorial: Acribia.

IUPAC, Nomenclatura de Compostos Orgânicos, Recomendações 1993, Publicações Científicas Blackwell, 1993. Editado por R Panico, WH Powell e Richer JC.

Junior, W.J.B. \& Bacha, L.M. 2003. Sistema digestivo. In: Atlas Colorido de Histologia Veterinária, 2. ed. São Paulo: Roca, 13, 121p.

Junqueira, L.C.V., Bignonas, G. \& Bretan, R.P. 1979. Picrosirius staining plus polarization microscopy, a specific method for collagen detection in the tissue sections. Histochem Journal. 11, 247- 255.

Kato, T., Hayashi, Y., Inoue, K. \& Yuasa, H. 2005. Glycerol absorption by Na+-dependent carrier-mediated transport in the closed loop of the rat small intestine. Biological \& Pharmaceutical Bulletin, 28, 553-555.

Lammers, P.J., Kerr, B.J., Weber, T.E., Dozier, W.A., Kidd, M.T., Bregendahl, K. \& Honeyman, M.S. 2008. Digestible and metabolizable energy of crude glycerol for growing pigs. Journal of Animal Science, 86, 602-608.

Macari, M; Furlan, R.L; Gonzales, E. 1994. Fisiologia aviária aplicada a frangos de corte. Jaboticabal: FUNEP/UNESP, 294p.

Maeda, N., Funahashi, T., Shimomura I. 2008. Metabolic impact of adipose and hepatic glycerol channels aquaporin 7 and aquaporin 9. Nature Clinical Practice Endocrinology \& Metabolism, 4, 627-634. 
MAPA. Ministério da Agricultura, Pecuária e Abastecimento. Instrução Normativa 42/2010 DE 17/12/2010 Disponível em: http://sistemasweb.agricultura.gov.br/sislegis/ action/detalhaAto.do?method=visualizarAtoP ortalMapa\&chave $=401297954<$ Acesso em: Julho 28 de 2015.

Marshman, E., Booth, C.,Potten, C.S. The intestinal epithelial stem cell. Bioessays, 24, 91-98.

Mclelland, J. 1975. Sistema Digestivo das Aves. In: Grossman, J.D., Sisson, S., Getty, R. Anatomia dos animais domésticos. 5ed. Rio de Janeiro: Guanabara Koongan, v.2, 63, 1441-1456.

Mendes, A.A., Naas, I. \& Macari, M. 2004. Saúde gastrointestinal, manejo e medidas para controlar as enfermidades gastrointestinais. In: Produção de frangos de corte. Campinas: FACTA, 505-251.

Menin, E., David, R.C., Matos, G.T. 1990. Anatomia funcional do tubo digestivo de Coragyps atratus brasiliensis Bonaparte, 1850 (Falconiformes, Cathartidae). Revista Ceres, 37, 398-420.

Menten, J.F.M., Miyada, V.S. \& Berenchtein, B. 2008. Glicerol na alimentação animal. In: Simpósio sobre Manejo e Nutrição de Aves e Suínos, 2008, Campinas, SP. Simpósio sobre Manejo e Nutrição de Aves e Suínos. Campinas, SP: Colégio Brasileiro de Nutrição Animal, 101-114.

Min, Y.N., Yan, F., Liu, F.Z., Coto, C. \& Waldroup, P.W. 2010. Glycerin-A New Energy Source for Poultry. International Journal of Poultry Science, 9, 1-4.

Mourot, J. Aumaitre, A., Mounier, A. Peiniau, P. \& Fracois, A.C. 1994. Nutritional and physiological effects of dietary glycerol in the growing pig. Consequences on fatty tissues and post mortem muscular parameters. Livestock Production Science, 38, 237-244.

Mowat, A.M. 2003. Anatomical basis of tolerance and immunity to intestinal antigens. Nature Reviews Immunology, 3, 331-341.

Oliveira, J. S., Antoniassiii, R., Freitas, S. C., Müller, M. D. 2013. Composição química da glicerina produzida por usinas de biodiesel no Brasil e potencial de uso na alimentação animal. Ciência Rural, 43, 509-512,
Piesker, M.EY. Dersjant-Li. 2006. Glycerol in Animal Nutrition - Versatile co-product of biodiesel production. Feedmagazine Kraftfutter, 89, 16-23.

Pinto, A.C.; Guarieiro, L.L N.; Rezende, M. J.C.; Ribeiro, N.M.; Torres, E.A.; Lopes, W.A.; Pereira, P.A.; De Andrade, J.B.; 2005. Biodiesel: an overview. Journal of the Brazilian Chemical Society, Campinas, 16, 1313-1330.

Santos, E.T. 2013. Glicerina como estratégia nutricional para frangos de corte criados em região de clima quente. Dissertação (Mestre em Zootecnia). Departamento de Zootecnia, Universidade Federal do Piauí. Bom Jesus.

Smith, A.L. \& Beal, R. The avian enteric immune system in health and disease. In: Davison, F., Kaspers, B., Schat, K.A. Avian Immunology. Academic Press, London, 2008, 13, 243-271.

Sturkie, P.D. 1991. Avian Physiology, New York: Cornell University Press, 217p.

Turk, D.E. 1998a. The anatomy of the avian digestive tract as related to feed utilization. Poultry Science, 77, 75-82,

Uni, Z. 2006. Early development of small intestinal function, in: Perry, G.C. Avian Gut Function in Health and Disease, Cab International, Wallingford, v.28, 3, 29-42.

Uni, Z., Noy, Y., Sklan, D. 1998. Posthatch developmentof muscosal function in the broiler small intestine. Poultry Science, 77, 75-82.

Viana, F.A.B. 2007. Guia terapêutico Veterinário. 2a edição. Lagoa Santa: Gráfica e Editora CEM.

Yamauchi K. 2002. Review on Chicken Intestinal Villus Histological Alterations Related with Intestinal Function. Journal of Poultry Science, 39, 229-242.

Yun, C.H., Lillehoj, H.S., Lillehoj, E.P. 2000. Intestinal immune responses to coccidiosis. Developmental and Comparative Immunology, 24, 303-324.

Recebido em Novembro 21, 2014.

Aceito em Junho 23, 2015

License information: This is an open-access article distributed under the terms of the Creative Commons Attribution License, which permits unrestricted use, distribution, and reproduction in any medium, provided the original work is properly cited. 